\title{
Septic Shock
}

\author{
John S. Giuliano Jr.
}

Section of Pediatric Critical Care, Yale University School of Medicine, New Haven, CT 06520-8064, USA

\begin{abstract}
Pediatric severe sepsis and septic shock continue to be significant causes of childhood morbidity and mortality worldwide. The following review will highlight some of the controversies surrounding the consensus definitions. It will chronicle recent clinical and translational research, focusing on pediatric sepsis-specific challenges investigators face. It will also address the pathophysiology of severe sepsis and septic shock, including up-to-date therapeutic recommendations.
\end{abstract}

Keywords: Pediatrics, children, PIRO, pathophysiology, therapy.

\section{INTRODUCTION}

Sepsis continues to be a significant cause of pediatric morbidity and mortality worldwide. According to the World Health Organization's 2009 statistics report, three of the top four killers of children less than five years of age are from infectious agents resulting in pneumonia, diarrhea and malaria [1]. Nationally, the most recent published data showed that in 1995 there were more than 42,000 cases of severe sepsis in children, with the highest incidence in the very young (infants $<12$ months of age) [2]. Severe sepsis is the fourth leading cause of death in infants behind congenital anomalies, prematurity and sudden infant death syndrome (SIDS). It is the second leading cause of death behind accidents in children greater than one year of age. Furthermore, children with sepsis represent a significant strain on the healthcare system and carry an overall hospital mortality rate of just over $10 \%[3,4]$.

In 2002, an international group of experts in the field of pediatric sepsis gathered to establish consensus definitions to aid specifically in establishing a common framework for clinical and translational research. This group defines pediatric sepsis as a continuum from the systemic inflammatory response syndrome (SIRS) to septic shock based upon age-specific vital sign and laboratory changes [5]. Severe sepsis is defined as a proven or suspected infection causing SIRS (i.e. sepsis) plus either cardiovascular organ dysfunction or acute respiratory distress syndrome (ARDS). Additionally, a child is classified as having severe sepsis if he or she possesses two or more other organ dysfunctions in the absence of cardiovascular organ dysfunction or ARDS [5]. Septic shock is a subset of severe sepsis, specifically defined as sepsis plus cardiovascular organ dysfunction [5]. In pediatric septic shock, and in contrast to the consensus definitions for adult septic shock, hypotension is not required for the diagnosis, as it is often a late finding [6]. Though a distinction is made between severe

*Address correspondence to this author at the Yale University School of Medicine, 333 Cedar Street, P.O. Box 208064, New Haven, CT 065208064, USA; Tel: 203-785-4651; Fax: 203-785-5833;

E-mail: john.giuliano@yale.edu sepsis and septic shock in the consensus guidelines, many investigators continue to group these patients together for research purposes. Therefore, both terms will be discussed interchangeably in the remainder of this review.

There continues to be controversy surrounding the consensus definitions for pediatric sepsis, especially since there are varying grades of disease within each category. In 2003, a group of adult sepsis researchers coined the "PIRO" concept at an international symposium on Intensive Care and Emergency Medicine [7]. PIRO is a new way of thinking about severely septic patients in an attempt to stage these patients, similarly to the way oncologists stage patients with the same type of cancer. The "P" stands for 'predisposition' and takes into account the patient's condition prior to entering the hospital. The "I" stands for 'infection or injury" that caused the current admission. The " $R$ " stands for 'response' and categorizes the patient's immune response to the infection or injury. Finally, the "O" stands for "organ dysfunction' and looks at the end result of the inflammatory cascade as a result of the infection or injury [7].

Formal applications of the "PIRO" concept in pediatric severe sepsis are lacking in the literature. However, many pediatric sepsis researchers have looked to biochemical markers to properly group patients for clinical trials and, more importantly, to initiate disease specific therapies more rapidly (i.e. "P" for 'predisposition'). Many of the biochemical markers have correlated well with severe sepsis but few are very specific. Among others, the most common biochemical markers measured in pediatric patients with severe sepsis and septic shock are interleukin-6 (IL-6), IL-8, C-reactive protein (CRP), serum amyloid protein (SAA), and procalcitonin (PCT) [8-18]. Depending on the optimal cutoff value chosen, some authors describe a similar area under the receiver operator curve (AUC) for IL-6 and IL-8 (0.87 and 0.87 , respectively) [19] whereas others have IL-6 performing better than IL-8 (0.77 and 0.44 , respectively) to predict severe bacterial infection in children [18]. SAA is potentially a better diagnostic marker with sensitivities, specificities, positive predictive values (PPV), and negative predictive values (NPV) all greater than $90 \%$ and an AUC 0.96 [20]. CRP levels are move variable for predicting severe bacterial 
infections in children. Sensitivities, specificities, PPV, NPV, and AUC range from $36-89 \%, 49-100 \%, 31.5-100 \%$, 76$96 \%$, and $0.43-0.93$, respectively [9-11, 16, 18-20].

The most robust marker of early severe bacterial infections in children and neonates appears to be PCT. Adding to its diagnostic capability, PCT levels appear to peak earlier, around 6 hours, compared to 24 hours for CRP, making it a potentially more helpful diagnostic tool [12]. PCT shares similar sensitivities, specificities, PPV, NPV and AUC ranges (90.5-100\%, 75-100\%, 51-100\%, 91-100\%, and $0.85-1.0$, respectively) as other markers but performs moderately better when compared head to head [9-11, 16, 18, 20]. Elevated PCT levels appear to correlate with an increased incidence and severity of septic shock, multiple organ dysfunction syndrome (MODS), and mortality in critically ill patients with infection [8-17]. Although, using PCT to diagnose severe bacterial infection remains controversial with some claiming that it does not add any additional information to the currently used and more readily available diagnostic markers $[17,21]$. Despite strong correlations, prospective data using PCT or other biochemical markers for clinical decision support are lacking.

No one biochemical marker is likely to be able to predict severity of illness with certainty. Instead, using multiple diagnostic markers will more likely lend the most assistance to a clinician's best judgment [22]. Combining IL- 6 and IL-8 improves the diagnostic sensitivity and NPV $(100 \%$ and $100 \%$, respectively) but decreases the specificity and PPV (55\% and 50\%, respectively) [19]. Similar results are obtained when combining IL-6 or IL-8 with CRP [19]. Likewise, the predictive sensitivity and NPV increases $(96 \%$ and $98 \%$, respectively) when PCT and CRP are combined but the specificity and PPV decreases $(67 \%$ and $46 \%$, respectively) [18]. Some of the newer biochemical markers showing some promise in pediatric septic shock include angiopoietin-2 (ang-2) and IL-13 [23, 24]. Unlike the previously mentioned biomarkers, ang-2, or more specifically the ang-2/1 ratio, may potentially lend itself to pharmacologic manipulation. Ang-2 is generally thought to promote capillary leak through the phosphorylation of myosin light chain kinase, the down-regulation of vascular endothelial cadherins and subsequent cellular contraction $[25,26]$. These effects appear to be reversible in vitro with the administration of ang-1 [27]. To date, prospective data targeting the manipulation of the ang-2/1 ratio is lacking in humans. Finally, others are searching for septic shockspecific gene polymorphisms and gene profiles to dictate therapy [28-31]. Again, these discoveries are still in the early investigative stages.

One characteristic that may add to the difficulty of finding a sepsis specific biochemical marker is that sepsis remains a very heterogeneous disease. In addition to its heterogeneity, age and developmental changes throughout childhood also make the management and study of pediatric sepsis challenging [32,33]. In the newborn population, for example, the presence of relative right ventricular hypertrophy, patent foramen ovale and ductus arteriosis, and increased pulmonary vascular resistance make the diagnosis and treatment of neonatal septic shock even more challenging. Further complicating the treatment of these patients with septic shock are their relative deficiencies in thyroid hormone, glycogen stores, calcium storage within an immature sarcoplasmic reticulum and thermoregulation. Few studies have adequately assessed the impact of these important developmental differences on the subsequent management and outcome of critically ill children with sepsis.

Regardless of developmental age, it is still not well understood why similar causative organisms result in severe sepsis and death in some children but not in others. For example, a wide range of $5 \%$ to $30 \%$ of children with an infection will progress to septic shock [34]. Unlike their adult counterparts who typically present with hypotension and normal to even high cardiac output (classically described as "warm shock"), pediatric patients often will present with low cardiac output and elevated systemic vascular resistance (classically described as "cold shock") [35]. The end organ dysfunction encountered in children with septic shock is often thought to be the result of decreased tissue oxygen consumption due to oxygen delivery deficits (i.e. tissue hypoxia) rather than oxygen extraction deficits, as seen in adult patients [36-38]. MODS is defined as having at least two or more failing organ systems and is commonly observed in children with severe sepsis and septic shock [3944]. As with adults, children with sepsis have a worse prognosis when MODS is present [45]. Many have shown that if MODS develops in a child with severe sepsis or septic shock, their risk of mortality is dramatically increased [41$44,46]$ as compared to patients without MODS [47, 48]. For example, in one epidemiologic study, children with severe sepsis who developed one organ failure had about a 7\% chance of death. This risk of death steadily increased to $53 \%$ when four organ systems were affected [2].

Maintaining adequate tissue oxygen delivery is the mainstay of pediatric sepsis treatment and will be discussed later in this review. However, new research has begun to alter this view. It is true that low cardiac output and decreased tissue oxygen delivery has been associated with a poor prognosis [36, 49-52]. Yet, both children and adults with normal oxygen delivery and poor oxygen extraction also tend to have poor prognoses $[53,54]$. Severe sepsis and septic shock should now be viewed as diseases of the microcirculation which lead to endothelial abnormalities, capillary leak, decreased tissue oxygen delivery and utilization, and ultimately end organ injury [40, 55-57].

Many postulate that the pathophysiology of sepsis can be explained by a dysregulation of microcirculatory homeostasis. A key molecule responsible for maintaining the microcirculation is nitric oxide (NO) and its primary substrate L-arginine. NO is one of the primary endogenous vasodilators affecting the cardiovascular system. An early review describes an increase production of systemic NO in sepsis but many of the studies referenced were performed with animal models [58]. A double blind randomized controlled trial attempting to block the excess NO seen in septic shock with NO inhibitors was ended early after poor results. Adult patients treated with NO inhibitors did possess improved blood pressures but at the expense of decreased cardiac output, pulmonary hypertension, heart failure and death [59]. Additionally, more recent data involving adult 
patients with septic shock reveals unchanged or decreased levels of systemic NO [60, 61].

Nevertheless, the previous studies may not be contradictory. The proinflammatory endothelial activation seen in sepsis does produce an increase in systemic NO production; however there may also be local microcirculatory reactive oxygen species and other scavengers leading to a relative NO deficiency in tissue beds [57]. This coupled with decreased endothelial NO bioavailability in sepsis will effectively shunt oxygen rich blood away from end organs and potentially lead to organ dysfunction [62]. In addition to shunting blood away from tissue beds, the decreased NO bioavailability may allow for the release of the vascular growth factor, ang- 2 , and its potential deleterious effects on the vascular endothelium which were previously discussed [63]. Further expanding on the concept of decreases in local bioavailability or NO production, a group investigated the role of endogenous asymmetric dimethylarginine (ADMA), a non-specific NO synthase inhibitor. They describe that the plasma Larginine:ADMA ratio is significantly reduced in adults with septic shock [64]. High ADMA, or low ratios, are associated with organ dysfunction due to the inhibition of $\mathrm{NO}$ production from the endothelium [64]. Unfortunately, the only pediatric study looking at ADMA levels in sepsis describes contradictory results to their adult counterparts. Weiss et. al. shows a decrease in ADMA in a pediatric septic shock cohort which results in an unchanged Larginine:ADMA ratio suggesting that the inhibition of endothelial NO synthase is less likely the predominate microcirculatory derangement in children with septic shock [65].

The concept that some patients are unable to increase oxygen consumption despite adequate oxygen delivery has sparked new research focusing intracellularly at mitochondria [66]. Mitochondrial dysfunction resulting in decreased ATP concentrations has been associated with organ dysfunction and mortality in septic adults [67]. In addition to decreases in ATP, some have described a decrease in total intracellular mitochondrial units as a result of sepsis-mediated mitoptosis [68]. Reactive oxygen and nitrogen species produced from innate immune and endothelial activation enter the cellular compartment further compounding mitochondrial dysfunction and cellular oxidative stress $[69,70]$.

Unfortunately, there is limited data utilizing antioxidents to improve mitochondrial function in pediatric septic shock patients [71]. Furthermore, what may benefit the adult patient with sepsis may not translate to the pediatric patient. For example, when measuring oxidative stress biomarkers, one group did not find significant differences when comparing septic children with healthy controls [72]. Therefore, current pediatric septic shock therapy recommendations continue to focus on maintaining appropriate oxygen delivery to the tissues through early goal-directed therapy. Reaching a goal cardiac index between 3.3-6.0 L/min $/ \mathrm{m}^{2}$ with rapid intravenous fluid administration within the first hour of resuscitation appears to improve survival $[6,49,52,73,74]$. The rapid reversal of shock improves outcome further if fluid is administered prior to the patient reaching the hospital [75].
Historically, intravenous pulmonary artery catheters were routinely used to directly measure cardiac output and to obtain pulmonary artery saturations in order to approximate cardiac output and volume status. Unfortunately, the complications associated with the placement of these catheters and their presence within the heart, coupled with challenging data interpretation and no clear evidence of improved outcome, have all but made these catheters obsolete in pediatric critical care [76, 77]. In their place, alternative ways of approximating cardiac output and volume status are being used and validated. Superior vena cava (SVC) oxygen saturation appears to be a reasonable surrogate for mixed venous oxygen saturation (covered in depth in the first article of this supplement), and several clinical studies using SVC oxygen saturation $\geq 70 \%$ as a resuscitation target have shown improved outcomes in both critically ill children and adults with severe sepsis $[6,74$, 78]. The resuscitation fluid administration regimen or specific type used (i.e. colloid or crystalloid) seems to be less important as long as it is administered quickly and titrated to restore the patient's mental status and end organ perfusion [6, 74, 79-81]. However, colloid solutions seemed to significantly reduce mortality in patients with severe sepsis from malaria [82]. Colloid fluid also increases systolic blood pressure and cardiac index in patients with dengue shock [83]. The previous studies may have shown statistical significance but many agree that the difference in fluid type may not be clinically relevant to change individual practice at this time.

Despite numerous studies and consensus statements about the benefit of early fluid resuscitation, the application of rapid fluid administration of $>40 \mathrm{~mL} / \mathrm{kg}$ within the first hour of therapy continues to be problematic. The 2007 pediatric and neonatal septic shock update from the American College of Critical Care Medicine recommends an even more rigorous fluid resuscitation goal. In this paper, 20$60 \mathrm{~mL} / \mathrm{kg}$ of resuscitation fluid is to be administered within the first 15 minutes in an attempt to achieve shock reversal [74]. Though data support these recommendations, strict adherence is difficult in clinical practice. One study identified lack of vascular access, lack of early septic shock diagnosis, and lack of treatment protocols as barriers to rapid fluid resuscitation [84]. For this reason, many institutions have started to create and use goal directed sepsis bundles. In a global performance improvement initiative targeted at improving the management of severe sepsis and septic shock in adults, the Surviving Sepsis Campaign focused primarily on establishing and implementing severe sepsis bundles [85]. A recent meta analysis showed a 1.91 odds of survival in critically ill adults with severe sepsis when bundled care was used compared to non-bundled care controls [86]. While the Surviving Sepsis Campaign excluded children, early studies have demonstrated the feasibility and ease of applying sepsis bundles to the pediatric population as well $[78,87,88]$.

Several studies have also demonstrated the adverse impact of fluid overload on survival, both in critically ill children and most recently in adults [5, 89-91]. Patients with stable hemodynamics and fluid overload may, in fact, require careful, ongoing titration of fluid management with control of the excess fluid through diuretic therapy. Furosemide and hydrochlorothiazide continue to be first-line diuretics and are preferred in patients without renal insufficiency. A minority 
of patients will develop acute kidney injury and severe fluid overload necessitating renal replacement therapy. Continuous renal replacement therapy (CRRT), which encompasses the continuous venovenous hemofiltration $(\mathrm{CVVH})$ modalities, provides continuous and measurable ultrafiltration rates without the variability seen with peritoneal dialysis (PD) or hemodialysis (HD) [92]. For these reasons, CRRT may be the preferred method of mechanical diuresis in hemodynamically fragile children with septic shock. Additionally, initiating CRRT early in the illness course before the child develops multiple organ failure or becomes excessively fluid overloaded (i.e. $<10$ $15 \%$ fluid overload) may be beneficial and improve outcome [89, 93, 94]. High volume CRRT has also been shown to remove pro- and anti-inflammatory cytokines by convection [95]. This type of therapy has been reported to improve survival in adult patients in some studies, but remains to be seen if this can translate into pediatric practice [96-98].

Besides rapid fluid resuscitation, early antibiotic use has also likely contributed to the improved outcomes seen over the years with septic shock. During the first 6 hours of hypotension onset in adults with septic shock, each hour appropriate antibiotic treatment is delayed decreases survival by $7.6 \%$ [99]. Bundled care has also helped to improve time to receiving appropriate antibiotics in this patient population [86]. In pediatrics, antibiotics are selected based on common age specific infectious organisms. Despite the eradication of the offending organism, many children continue to deteriorate due to an overabundance of inflammatory cytokines and an uncontrolled inflammatory response. Some investigators have begun to look at modulating the immune response, as seen in the use of pentoxifylline with septic premature babies [100]. However, the most extensively studied and controversial immune modulator remains corticosteroid therapy. It has been well established that critically ill children with severe sepsis develop adrenal insufficiency which can result in low cortisol levels. Treatment with corticosteroids seems to improve cardiovascular parameters but not necessarily outcome [101105]. Septic shock alone and many of the medications administered while in shock (i.e. one dose of etomidate for endotracheal intubation), can exacerbate adrenal insufficiency [106-108]. Because of this, etomidate use is not recommended in pediatric septic shock [74]. Unfortunately, there are limited data in the form of clinical trials in children with severe sepsis or septic shock addressing routine corticosteroid therapy in the absence of adrenal insufficiency. A review of the corticosteroid debate describes the lack of a clear consensus agreement about "adequate" host stress response as one of the main barriers. This, coupled with a lack of clinical equipoise, has posed a significant obstacle to pediatric corticosteroid trials [109].

In addition to antibiotics and intravenous fluids, a vast majority of patients with septic shock will receive some type of vasopressor or inotropic support. One of the major changes in the 2007 update on hemodynamic support for pediatric and neonatal septic shock from the American College of Critical Care Medicine is the recommendation to start inotropes peripherally until placement of a central venous catheter can be achieved [74]. Dopamine at doses less than $10 \mu \mathrm{g} / \mathrm{kg} / \mathrm{min}$ remains the first-line inotrope at most institutions. Since dopamine causes vasoconstriction by releasing norepinephrine from sympathetic nerve fibers, catecholamine deplete children with septic shock may not respond. For this reason, many will utilize epinephrine at doses less than $0.3 \mu \mathrm{g} / \mathrm{kg} / \mathrm{min}$ for first-line inotropy as well.

Whether from intensive care therapies or insulin resistance due to critical illness, many children with septic shock will develop hyperglycemia. Many retrospective studies in pediatric critical care have shown an association between hyperglycemia and organ dysfunction, risk of death and longer ICU length of stay [110-113]. Since much of the hyperglycemia recommendations are based on initial adult data, many in pediatric critical care have questioned appropriate glucose control in this patient population [114]. A recent randomized controlled trial demonstrated shorter intensive care unit stays and lower C-reactive protein levels in children aggressively treated with insulin therapy to control hyperglycemia. However, a large percentage of this cohort also developed profound hypoglycemia [115]. Though dangerous in all patient populations, the developing pediatric and neonatal brain can incur more severe, irreversible damage when faced with hypoglycemia [116]. As was seen with the activated protein $\mathrm{C}$ pediatric trials, this may be yet another adult septic shock therapy that is not translatable to pediatric patients [117]. Further adding to the controversy, the Normoglycemia in Intensive Care Evaluation and Survival Using Glucose Algorithm Regulation (NICE-SUGAR) study recently refuted the original adult study and showed a mortality increase in critically ill patients managed with tight glucose control [118]. Until a definitive large prospective trial in pediatric septic shock is completed, glucose control recommendations cannot be made.

Considered by many as a last option therapy, extracorporeal membrane oxygenation (ECMO) has become a more popular septic shock treatment modality in many pediatric tertiary care centers. ECMO centers have reported close to $84 \%$ survival in neonatal sepsis [119]. The data is less encouraging in pediatric sepsis, with survival percentages ranging from $37 \%$ to $66 \%$ [120-124]. The Extracorporeal Life Support Organization (ELSO) reports a national survival rate of $73 \%$ when neonates are placed on ECMO for sepsis or pneumonia. The survival rate is down to $57 \%$ when older children are placed on ECMO for various infectious lung pathogens [125].

In conclusion, the correct diagnosis continues to be of utmost importance especially with the increasing problem of antibiotic resistance. Biomarkers, such as PCT, need to be more thoroughly evaluated in a prospective decision-making manner before they can direct patient care. Additionally, more recent data has begun to shift our understanding of the pathophysiology of pediatric sepsis. It is becoming more evident that deficiencies in tissue oxygen consumption are the result of derangements at the microvascular level, specifically involving the endothelium and mitochondria. Septic shock should now be viewed as the result of [1] inadequate tissue oxygen delivery (systemic hypoxia) and [2] inadequate tissue oxygen utilization by the mitochondria (cytopathic hypoxia) [70]. New therapies should focus specifically on augmenting the vascular endothelium to limit capillary leak and prevent wide variations in tone. Angiopoietins appear to be the likely candidates. Antioxidant 
research to improve mitochondrial function is encouraging in animal studies but more data is needed before these can be implemented in pediatric patients. Until then we are left with resuscitation fluids, antibiotics and other supportive measures as the only universally accepted therapies for pediatric severe sepsis and septic shock.

\section{CONFLICT OF INTEREST}

The authors confirm that this article content has no conflicts of interest.

\section{ACKNOWLEDGEMENTS}

Declared none.

\section{REFERENCES}

[1] Organization WH. World Health Statistics. 2009; pp. 1-149.

[2] Watson RS, Carcillo JA, Linde-Zwirble WT, Clermont G, Lidicker $\mathrm{J}$, Angus DC. The epidemiology of severe sepsis in children in the United States. Am J Respir Crit Care Med 2003; 167(5): 695-701.

[3] Angus DC, Linde-Zwirble WT, Lidicker J, Clermont G, Carcillo J, Pinsky MR. Epidemiology of severe sepsis in the United States: analysis of incidence, outcome, and associated costs of care. Crit Care Med 2001; 29(7): 1303-10.

[4] Watson RS, Carcillo JA. Scope and epidemiology of pediatric sepsis. Pediatr Crit Care Med 2005; 6(3 Suppl): S3-5.

[5] Goldstein B, Giroir B, Randolph A. International pediatric sepsis consensus conference: definitions for sepsis and organ dysfunction in pediatrics. Pediatr Crit Care Med 2005; 6(1): 2-8.

[6] Carcillo JA, Fields AI. Clinical practice parameters for hemodynamic support of pediatric and neonatal patients in septic shock. Crit Care Med 2002; 30(6): 1365-78.

[7] Angus DC, Burgner D, Wunderink R, et al. The PIRO concept: P is for predisposition. Crit Care 2003; 7(3): 248-51.

[8] Assicot M, Gendrel D, Carsin H, Raymond J, Guilbaud J, Bohuon C. High serum procalcitonin concentrations in patients with sepsis and infection. Lancet 1993; 341(8844): 515-8.

[9] Carrol ED, Mankhambo LA, Jeffers G, et al. The diagnostic and prognostic accuracy of five markers of serious bacterial infection in Malawian children with signs of severe infection. PLoS One 2009; 4(8): e6621.

[10] Carrol ED, Newland P, Riordan FA, Thomson AP, Curtis N, Hart CA. Procalcitonin as a diagnostic marker of meningococcal disease in children presenting with fever and a rash. Arch Dis Child 2002; 86(4): 282-5.

[11] Carrol ED, Newland P, Thomson AP, Hart CA. Prognostic value of procalcitonin in children with meningococcal sepsis. Crit Care Med 2005; 33(1): 224-5.

[12] Casado-Flores J, Blanco-Quiros A, Asensio J, Arranz E, Garrote JA, Nieto M. Serum procalcitonin in children with suspected sepsis: a comparison with C-reactive protein and neutrophil count. Pediatr Crit Care Med 2003; 4(2): 190-5.

[13] Fioretto JR, Martin JG, Kurokawa CS, et al. Comparison between procalcitonin and C-reactive protein for early diagnosis of children with sepsis or septic shock. Inflamm Res 2010; 59(8): 581-6

[14] Han YY, Doughty LA, Kofos D, Sasser H, Carcillo JA. Procalcitonin is persistently increased among children with poor outcome from bacterial sepsis. Pediatr Crit Care Med 2003; 4(1): 21-5.

[15] Hatherill M, Tibby SM, Turner C, Ratnavel N, Murdoch IA. Procalcitonin and cytokine levels: relationship to organ failure and mortality in pediatric septic shock. Crit Care Med 2000; 28(7): 2591-4.

[16] Leclerc F, Leteurtre S, Noizet $O$, et al. Procalcitonin as a prognostic marker in children with meningococcal septic shock. Arch Dis Child 2002; 87(5): 450.

[17] Ugarte H, Silva E, Mercan D, De Mendonça A, Vincent JL. Procalcitonin used as a marker of infection in the intensive care unit. Crit Care Med 1999; 27(3): 498-504.

[18] Lacour AG, Gervaix A, Zamora SA, et al. Procalcitonin, IL-6, IL8, IL-1 receptor antagonist and C-reactive protein as identificators of serious bacterial infections in children with fever without localising signs. Eur J Pediatr 2001; 160(2): 95-100.
[19] Mehr SS, Doyle LW, Rice GE, Vervaart P, Henschke P. Interleukin-6 and interleukin-8 in newborn bacterial infection. Am J Perinatol 2001; 18(6): 313-24.

[20] Enguix A, Rey C, Concha A, Medina A, Coto D, Diéguez MA Comparison of procalcitonin with $\mathrm{C}$-reactive protein and serum amyloid for the early diagnosis of bacterial sepsis in critically ill neonates and children. Intensive Care Med 2001;27(1): 211-5.

[21] Bonac B, Derganc M, Wraber B, Hojker S. Interleukin-8 and procalcitonin in early diagnosis of early severe bacterial infection in critically ill neonates. Pflugers Arch 2000; 440(5 Suppl): R72-4.

[22] de Kruif MD, Limper M, Gerritsen $H$, et al. Additional value of procalcitonin for diagnosis of infection in patients with fever at the emergency department. Crit Care Med 2010; 38(2): 457-63.

[23] Blanco-Quiros A, Casado-Flores J, Garrote AJA, et al. Interleukin13 is involved in the survival of children with sepsis. Acta Paediatr 2005; 94(12): 1828-31.

[24] Giuliano JS Jr, Lahni PM, Harmon K, et al. Admission angiopoietin levels in children with septic shock. Shock 2007; 28(6): 650-4

[25] Parikh SM, Mammoto T, Schultz A, et al. Excess circulating angiopoietin-2 may contribute to pulmonary vascular leak in sepsis in humans. PLoS Med 2006; 3(3): e46.

[26] Gallagher DC, Bhatt RS, Parikh SM, et al. Angiopoietin 2 is a potential mediator of high-dose interleukin 2-induced vascular leak. Clin Cancer Res 2007; 13(7): 2115-20.

[27] Mammoto T, Parikh SM, Mammoto A, et al. Angiopoietin-1 requires p190 RhoGAP to protect against vascular leakage in vivo. J Biol Chem 2007; 282(33): 23910-8,

[28] Wong HR, Cvijanovich N, Allen GL, et al. Genomic expression profiling across the pediatric systemic inflammatory response syndrome, sepsis, and septic shock spectrum. Crit Care Med 2009; 37(5): 1558-66.

[29] Wong HR, Cvijanovich N, Lin R, et al. Identification of pediatric septic shock subclasses based on genome-wide expression profiling. BMC Med 2009; 7: 34.

[30] Bunker-Wiersma HE, Koopmans RP, Kuipers TW, et al. Single nucleotide polymorphisms in genes of circulatory homeostasis in surviving pediatric intensive care patients with meningococcal infection. Pediatr Crit Care Med 2008; 9(5): 517-23.

[31] Gordon AC, Waheed U, Hansen TK, et al. Mannose-binding lectin polymorphisms in severe sepsis: relationship to levels, incidence, and outcome. Shock 2006; 25(1): 88-93.

[32] Wheeler DS WH, Zingarelli B. Children are not Small Adults! Open Inflamm J 2011; 4: 4-12.

[33] Wynn J, Cornell TT, Wong HR, et al. The host response to sepsis and developmental impact. Pediatrics 2010; 125(5): 1031-41.

[34] Zimmerman JJ. Sepsis/septic shock. In: Pediatric critical care. Fuhrman BP, Zimmerman JJ, Eds. $2^{\text {nd }}$ ed. Mosby, MO: St. Louis 1998, pp. 1088-100.

[35] Dellinger RP, Levy MM, Carlet JM, et al. Surviving Sepsis Campaign: international guidelines for management of severe sepsis and septic shock: 2008. Crit Care Med 2008; 36(1): 296-327.

[36] Carcillo JA, Pollack MM, Ruttimann UE, et al. Sequential physiologic interactions in pediatric cardiogenic and septic shock. Crit Care Med 1989; 17(1): 12-6.

[37] Kaufman BS, Rackow EC, Falk JL. The relationship between oxygen delivery and consumption during fluid resuscitation of hypovolemic and septic shock. Chest 1984; 85(3): 336-40.

[38] Lucking SE, Williams TM, Chaten FC, et al. Dependence of oxygen consumption on oxygen delivery in children with hyperdynamic septic shock and low oxygen extraction. Crit Care Med 1990; 18(12): 1316-9.

[39] American College of Chest Physicians/Society of Critical Care Medicine Consensus Conference: definitions for sepsis and organ failure and guidelines for the use of innovative therapies in sepsis. Crit Care Med 1992; 20(6): 864-74.

[40] Nguyen T, Hall M, Han Y, et al. Microvascular thrombosis in pediatric multiple organ failure: Is it a therapeutic target? Pediatr Crit Care Med 2001; 2(3): 187-96.

[41] Wilkinson JD, Pollack MM, Ruttimann UE, et al. Outcome of pediatric patients with multiple organ system failure. Crit Care Med 1986; 14(4): 271-4.

[42] Wilkinson JD, Pollack MM, Glass NL, et al. Mortality associated with multiple organ system failure and sepsis in pediatric intensive care unit. J Pediatr 1987; 111(3): 324-8. 
[43] Proulx F, Fayon M, Farrell CA, et al. Epidemiology of sepsis and multiple organ dysfunction syndrome in children. Chest 1996; 109(4): 1033-7.

[44] Proulx F, Gauthier M, Nadeau D, et al. Timing and predictors of death in pediatric patients with multiple organ system failure. Crit Care Med 1994; 22(6): 1025-31.

[45] Leclerc F, Leteurtre S, Duhamel A, et al. Cumulative influence of organ dysfunctions and septic state on mortality of critically ill children. Am J Respir Crit Care Med 2005; 171(4): 348-53.

[46] Odetola FO, Gebremariam A, Freed GL. Patient and hospital correlates of clinical outcomes and resource utilization in severe pediatric sepsis. Pediatrics 2007; 119(3): 487-94.

[47] Duke TD, Butt W, South M. Predictors of mortality and multiple organ failure in children with sepsis. Intensive Care Med 1997; 23(6): 684-92.

[48] Kutko MC, Calarco MP, Flaherty MB, et al. Mortality rates in pediatric septic shock with and without multiple organ system failure. Pediatr Crit Care Med 2003; 4(3): 333-7.

[49] Pollack MM, Fields AI, Ruttimann UE. Distributions of cardiopulmonary variables in pediatric survivors and nonsurvivors of septic shock. Crit Care Med 1985; 13(6): 454-9.

[50] Monsalve F, Rucabado L, Salvador A, et al. Myocardial depression in septic shock caused by meningococcal infection. Crit Care Med 1984; 12(12): 1021-3.

[51] Feltes TF, Pignatelli R, Kleinert S, et al. Quantitated left ventricular systolic mechanics in children with septic shock utilizing noninvasive wall-stress analysis. Crit Care Med 1994; 22(10): 1647-58.

[52] Ceneviva G, Paschall JA, Maffei F, et al. Hemodynamic support in fluid-refractory pediatric septic shock. Pediatrics 1998; 102(2): e19.

[53] Pollack MM, Fields AI, Ruttimann UE. Sequential cardiopulmonary variables of infants and children in septic shock. Crit Care Med 1984; 12(7): 554-9.

[54] Hayes MA, Timmins AC, Yau EH, et al. Oxygen transport patterns in patients with sepsis syndrome or septic shock: influence of treatment and relationship to outcome. Crit Care Med 1997; 25(6): 926-36.

[55] Hinshaw LB. Sepsis/septic shock: participation of the microcirculation: an abbreviated review. Crit Care Med 1996; 24(6): 1072-8.

[56] Wheeler DS WH, Shanley TP. Pediatric Critical Care Medicine: Basic Science and Clinical Evidence. $1^{\text {st }}$ ed. London: Springer; 2007; pp. 118-25, 1421-44.

[57] Trzeciak S, Cinel I, Phillip DR, et al. Resuscitating the microcirculation in sepsis: the central role of nitric oxide, emerging concepts for novel therapies, and challenges for clinical trials. Acad Emerg Med 2008; 15(5): 399-413.

[58] Vincent JL, Zhang H, Szabo C, et al. Effects of nitric oxide in septic shock. Am J Respir Crit Care Med 2000; 161(6): 1781-5.

[59] Lopez A, Lorente JA, Steingrub J, et al. Multiple-center, randomized, placebo-controlled, double-blind study of the nitric oxide synthase inhibitor 546C88: effect on survival in patients with septic shock. Crit Care Med 2004; 32(1): 21-30.

[60] Kao CC, Bandi V, Guntupalli KK, et al. Arginine, citrulline and nitric oxide metabolism in sepsis. Clin Sci (Lond) 2009; 117(1): 23-30.

[61] Luiking YC, Poeze M, Ramsay G, et al. Reduced citrulline production in sepsis is related to diminished de novo arginine and nitric oxide production. Am J Clin Nutr 2009; 89(1): 142-52.

[62] Davis JS, Yeo TW, Thomas JH, et al. Sepsis-associated microvascular dysfunction measured by peripheral arterial tonometry: an observational study. Crit Care 2009; 13(5): R155.

[63] Davis JS, Yeo TW, Piera KA, et al. Angiopoietin-2 is increased in sepsis and inversely associated with nitric oxide-dependent microvascular reactivity. Crit Care 2010; 14(3): R89.

[64] Davis JS, Darcy CJ, Yeo TW, et al. Asymmetric dimethylarginine, endothelial nitric oxide bioavailability and mortality in sepsis. PLoS One 2011; 6(2): e17260.

[65] Weiss SL, Haymond S, Ralay Ranaivo H, et al. Evaluation of asymmetric dimethylarginine, arginine, and carnitine metabolism in pediatric sepsis. Pediatr Crit Care Med 2012; 13(4): e210-8.

[66] Fink MP. Cytopathic hypoxia. Mitochondrial dysfunction as mechanism contributing to organ dysfunction in sepsis. Crit Care Clin 2001; 17(1): 219-37.
[67] Brealey D, Brand M, Hargreaves I, et al. Association between mitochondrial dysfunction and severity and outcome of septic shock. Lancet 2002; 360(9328): 219-23.

[68] Fredriksson K, Hammarqvist F, Strigard K, et al. Derangements in mitochondrial metabolism in intercostal and leg muscle of critically ill patients with sepsis-induced multiple organ failure. Am J Physiol Endocrinol Metab 2006; 291(5): E1044-50.

[69] Andrades ME, Morina A, Spasic S, et al. Bench-to-bedside review: sepsis - from the redox point of view. Crit Care 2011; 15(5): 230.

[70] Huet O, Dupic L, Harrois A, et al. Oxidative stress and endothelial dysfunction during sepsis. Front Biosci 2011; 16: 1986-95.

[71] von Dessauer B, Bongain J, Molina V, et al. Oxidative stress as a novel target in pediatric sepsis management. J Crit Care 2010; 26(1): 103 e101-7.

[72] Cherian S, Jameson S, Rajarajeswari C, et al. Oxidative stress in sepsis in children. Indian J Med Res 2007; 125(2): 143-8.

[73] Carcillo JA, Davis AL, Zaritsky A. Role of early fluid resuscitation in pediatric septic shock. JAMA 1991; 266(9): 1242-5.

[74] Brierley J, Carcillo JA, Choong K, et al. Clinical practice parameters for hemodynamic support of pediatric and neonatal septic shock: 2007 update from the American College of Critical Care Medicine. Crit Care Med 2009; 37(2): 666-88.

[75] Han YY, Carcillo JA, Dragotta MA, et al. Early reversal of pediatric-neonatal septic shock by community physicians is associated with improved outcome. Pediatrics 2003; 112(4): 793-9.

[76] Evans DC, Doraiswamy VA, Prosciak MP, et al. Complications associated with pulmonary artery catheters: a comprehensive clinical review. Scand J Surg 2009; 98(4)199-208.

[77] Ramsay J. Pro: Is the pulmonary artery catheter dead? J Cardiothorac Vasc Anesth 2007; 21(1): 144-6.

[78] de Oliveira CF, de Oliveira DS, Gottschald AF, et al. ACCM/PALS haemodynamic support guidelines for paediatric septic shock: an outcomes comparison with and without monitoring central venous oxygen saturation. Intensive Care Med 2008; 34(6): 1065-75.

[79] Wills BA, Nguyen MD, Ha TL, et al. Comparison of three fluid solutions for resuscitation in dengue shock syndrome. N Engl $\mathrm{J}$ Med 2005; 353(9): 877-89.

[80] Ngo NT, Cao XT, Kneen R, et al. Acute management of dengue shock syndrome: a randomized double-blind comparison of 4 intravenous fluid regimens in the first hour. Clin Infect Dis 2001; 32(2): 204-13.

[81] Santhanam I, Sangareddi S, Venkataraman S, et al. A prospective randomized controlled study of two fluid regimens in the initial management of septic shock in the emergency department. Pediatr Emerg Care 2008; 24(10): 647-55.

[82] Maitland K, Pamba A, English M, et al. Randomized trial of volume expansion with albumin or saline in children with severe malaria: preliminary evidence of albumin benefit. Clin Infect Dis 2005; 40(4): 538-45

[83] Dung NM, Day NP, Tam DT, et al. Fluid replacement in dengue shock syndrome: a randomized, double-blind comparison of four intravenous-fluid regimens. Clin Infect Dis 1999; 29(4): 787-94.

[84] Oliveira CF, Nogueira de Sa FR, Oliveira DS, et al. Time- and fluid-sensitive resuscitation for hemodynamic support of children in septic shock: barriers to the implementation of the American College of Critical Care Medicine/Pediatric Advanced Life Support Guidelines in a pediatric intensive care unit in a developing world. Pediatr Emerg Care 2008; 24(12): 810-5.

[85] Levy MM, Dellinger RP, Townsend SR, et al. The Surviving Sepsis Campaign: results of an international guideline-based performance improvement program targeting severe sepsis. Intensive Care Med 2010; 36(2): 222-31.

[86] Barochia AV, Cui X, Vitberg D, et al. Bundled care for septic shock: an analysis of clinical trials. Crit Care Med 2009; 38(2): 668-78.

[87] Larsen GY, Mecham N, Greenberg R. An emergency department septic shock protocol and care guideline for children initiated at triage. Pediatrics 2011; 127(6): e1585-92.

[88] Cruz AT, Perry AM, Williams EA, et al. Implementation of goaldirected therapy for children with suspected sepsis in the emergency department. Pediatrics 2011; 127(3): e758-66.

[89] Goldstein SL, Somers MJ, Baum MA, et al. Pediatric patients with multi-organ dysfunction syndrome receiving continuous renal replacement therapy. Kidney Int 2005; 67(2): 653-8. 
[90] Michael M, Kuehnle I, Goldstein SL. Fluid overload and acute renal failure in pediatric stem cell transplant patients. Pediatr Nephrol 2004; 19(1): 91-5.

[91] Sutherland SM, Zappitelli M, Alexander SR, et al. Fluid overload and mortality in children receiving continuous renal replacement therapy: the prospective pediatric continuous renal replacement therapy registry. Am J Kidney Dis 2010; 55(2): 316-25.

[92] Brophy PD. Renal supportive therapy for pediatric acute kidney injury in the setting of multiorgan dysfunction syndrome/sepsis. Semin Nephrol 2008; 28(5): 457-69.

[93] Hayes LW, Oster RA, Tofil NM, et al. Outcomes of critically ill children requiring continuous renal replacement therapy. J Crit Care 2009; 24(3): 394-400.

[94] Foland JA, Fortenberry JD, Warshaw BL, et al. Fluid overload before continuous hemofiltration and survival in critically ill children: a retrospective analysis. Crit Care Med 2004; 32(8): 1771-6.

[95] Ronco C, Tetta C, Mariano F, et al. Interpreting the mechanisms of continuous renal replacement therapy in sepsis: the peak concentration hypothesis. Artif Organs 2003; 27(9): 792-801.

[96] Honore PM, Joannes-Boyau O, Boer W, et al. High-volume hemofiltration in sepsis and SIRS: current concepts and future prospects. Blood Purif 2009; 28(1): 1-11.

[97] Ronco C, Bellomo R, Homel P, et al. Effects of different doses in continuous veno-venous haemofiltration on outcomes of acute renal failure: a prospective randomised trial. Lancet 2000; 356(9223): 26-30

[98] Piccinni P, Dan M, Barbacini S, et al. Early isovolaemic haemofiltration in oliguric patients with septic shock. Intensive Care Med 2006; 32(1): 80-6.

[99] Kumar A, Roberts D, Wood KE, et al. Duration of hypotension before initiation of effective antimicrobial therapy is the critical determinant of survival in human septic shock. Crit Care Med 2006; 34(6): 1589-96.

[100] Lauterbach R, Pawlik D, Kowalczyk D, et al. Effect of the immunomodulating agent, pentoxifylline, in the treatment of sepsis in prematurely delivered infants: a placebo-controlled, double-blind trial. Crit Care Med 1999; 27(4): 807-14.

[101] Pizarro CF, Troster EJ. Adrenal function in sepsis and septic shock. J Pediatr (Rio J) 2007; 83(5 Suppl): S155-162.

[102] Sarthi M, Lodha R, Vivekanandhan S, et al. Adrenal status in children with septic shock using low-dose stimulation test. Pediatr Crit Care Med 2007; 8(1): 23-8.

[103] Casartelli CH, Garcia PC, Branco RG, et al. Adrenal response in children with septic shock. Intensive Care Med 2007; 33(9): 160913 .

[104] Hatherill M, Tibby SM, Hilliard T, et al. Adrenal insufficiency in septic shock. Arch Dis Child 1999; 80(1): 51-5.

[105] Baker CF, Barks JD, Engmann C, et al. Hydrocortisone administration for the treatment of refractory hypotension in critically ill newborns. J Perinatol 2008; 28(6): 412-9.

[106] Sprung CL, Annane D, Keh D, et al. Hydrocortisone therapy for patients with septic shock. N Engl J Med 2008; 358(2): 111-24.
[107] Wagner RL, White PF, Kan PB, et al. Inhibition of adrenal steroidogenesis by the anesthetic etomidate. N Engl J Med 1984; 310(22): 1415-21.

[108] Bloomfield R, Noble DW. Etomidate, pharmacological adrenalectomy and the critically ill: a matter of vital importance. Crit Care 2006; 10(4): 161.

[109] Zimmerman JJ. A history of adjunctive glucocorticoid treatment for pediatric sepsis: moving beyond steroid pulp fiction toward evidence-based medicine. Pediatr Crit Care Med 2007; 8(6): 530-9.

[110] Kyle UG, Coss Bu JA, Kennedy CE, et al. Organ dysfunction is associated with hyperglycemia in critically ill children. Intensive Care Med 2009; 36(2): 312-20.

[111] Srinivasan V, Spinella PC, Drott HR, et al. Association of timing, duration, and intensity of hyperglycemia with intensive care unit mortality in critically ill children. Pediatr Crit Care Med 2004; 5(4): $329-36$

[112] Faustino EV, Apkon M. Persistent hyperglycemia in critically ill children. J Pediatr 2005; 146(1): 30-4

[113] Branco RG, Garcia PC, Piva JP, et al. Glucose level and risk of mortality in pediatric septic shock. Pediatr Crit Care Med 2005; 6(4): 470-2.

[114] van den Berghe G, Wouters P, Weekers F, et al. Intensive insulin therapy in the critically ill patients. N Engl J Med 2001; 345(19): $1359-67$

[115] Vlasselaers D, Milants I, Desmet L, et al. Intensive insulin therapy for patients in paediatric intensive care: a prospective, randomised controlled study. Lancet 2009; 373(9663): 547-56.

[116] Straussman S, Levitsky LL. Neonatal hypoglycemia. Curr Opin Endocrinol Diabetes Obes 2009; 17(1): 20-4.

[117] Nadel S, Goldstein B, Williams MD, et al. Drotrecogin alfa (activated) in children with severe sepsis: a multicentre phase III randomised controlled trial. Lancet 2007; 369(9564): 836-43.

[118] Finfer S, Chittock DR, Su SY, et al. Intensive versus conventional glucose control in critically ill patients. N Engl J Med 2009; 360(13): 1283-97.

[119] Bartlett RH, Roloff DW, Custer JR, et al. Extracorporeal life support: the University of Michigan experience. JAMA 2000; 283(7): 904-8.

[120] Meyer DM, Jessen ME. Results of extracorporeal membrane oxygenation in children with sepsis. The Extracorporeal Life Support Organization. Ann Thorac Surg 1997; 63(3): 756-61.

[121] Beca J, Butt W. Extracorporeal membrane oxygenation for refractory septic shock in children. Pediatrics 1994; 93(5): 726-9.

[122] Goldman AP, Kerr SJ, Butt W, et al. Extracorporeal support for intractable cardiorespiratory failure due to meningococcal disease. Lancet 1997; 349(9050): 466-9.

[123] Luyt DK, Pridgeon J, Brown J, et al. Extracorporeal life support for children with meningococcal septicaemia. Acta Paediatr 2004; 93(12): 1608-11.

[124] Maclaren G, Butt W, Best D, et al. Extracorporeal membrane oxygenation for refractory septic shock in children: one institution's experience. Pediatr Crit Care Med 2007; 8(5): 447-51.

[125] Extracorporeal Life Support Organization. In: http://www.elso.me d.umich.edu/ 